\title{
The Prevalence of Schistosoma mansoni is affected by Taenia spp. and Soil-transmitted Helminths
}

\author{
Munir Chamone ${ }^{1}$, Gregorio Saraiva Atuncar ${ }^{2}$, Alan Lane de Melo ${ }^{3 *}$ \\ ${ }^{I}$ Departamento de Bioquímica-Imunologia, Instituto de Ciências Biológicas, Universidade Federal de \\ Minas Gerais, Belo Horizonte, MG, Brasil \\ ${ }^{2}$ Departamento de Estatística, Instituto de Ciências Exatas, Universidade Federal de Minas Gerais, Belo \\ Horizonte, MG, Brasil \\ ${ }^{3}$ Departamento de Parasitologia, Instituto de Ciências Biológicas, Universidade Federal de Minas \\ Gerais, Belo Horizonte, $M G$, Brasil
}

*Corresponding Author: Alan Lane de Melo, Departamento de Parasitologia, Instituto de Ciências Biológicas, Universidade Federal de Minas Gerais, Av. Antonio Carlos 6627, CEP 30.270-901 Belo Horizonte, MG, Brasil.

\begin{abstract}
The average prevalence of Schistosoma mansoni infections in Brazil is related to Taenia spp. (presence/absence) and is modulated by Strongyloides stercoralis, Ascaris lumbricoides, Trichuris trichura, or hookworm (Ancylostoma and/or Necator) species. The high score average prevalence of schistosomiasis was seen in strata whose Taenia spp. was absent. In contrast, the lower score average prevalence of schistosomiasis was seen in strata whose Taenia spp. was present irrespective to prevalence level of Strongyloides, Ascaris, Trichuris, or hookworm.
\end{abstract}

Keywords: Helminth parasites, Prevalence, Schistosomiasis, Ascaris lumbricoides, Hookworm, Strongyloides stercoralis, Trichuris trichura

\section{INTRODUCTION}

The Taenia solium infection was included by the World Health Organization in its strategic plans for the control of neglected tropical diseases [1]. Despite to be considered by some authors as the most neglected of the neglected tropical diseases [2,3], the strongyloidiasis, is an important medically problem, due the parasitic helminth Strongyloides, an aggressive parasite, since it may cause hyperinfection and dissemination in complicated strongyloidiasis through auto-infection [3]. Additionally, human schistosomiasis is a major source of morbidity. Some situations are reported in which the schistosome and Ascaris lumbricoides, Trichuris trichura, or hookworm (Ancylostoma and/or Necator) infections in the human results in a pattern of schistosomiasis which differs from the isolated Schistosoma mansoni infections, suggesting a synergistic or antagonism relationship between these species [4-10]. In spite of the fact that Taenia spp., Strongyloides stercoralis, A. lumbricoides, $T$. trichura, and hookworm infections frequently occur in regions where $S$. mansoni is endemic, the statistical association of those helminth species with Schistosoma has not been highlight on several studies. So far, it would indicate that something should be re-examined. Using the Brazilian bibliographic database it was pursued the effect of Taenia spp., Strongyloides, Ascaris, Trichuris, and hookworm species in the average prevalence of $S$. mansoni infections.

\section{Material AND MethodS}

Scientific publications between 1974 and 2013 for surveys conducted in Brazil of all age ('entire community') and children-based surveys available in Portuguese and English-language were eligible for inclusion. The search included only studies that had sample size higher than 30 [11] and were all positive for the presence of $S$. mansoni eggs on fecal examinations and present information for Ascaris, Trichuris, hookworms, Taenia spp., and S. stercoralis using the parasitological technique. Score prevalences of all parasites are registered, and in some cases the prevalent rate was recalculated (Boxes 1 and 2). 
The Prevalence of Schistosoma mansoni is affected by Taenia spp. and Soil-transmitted Helminths

Box 1. Primary source of analysed data from Brazilian literature showing prevalence of helminhts in areas without Taenia spp. transmission

\begin{tabular}{|c|c|c|c|c|c|c|c|c|}
\hline Author & Localities & $\mathbf{N}$ & $\mathbf{S m}$ & Asc & Tri & Tae & Hoo & Ss \\
\hline 1. Siqueira 2011 & MG & 201 & 28.9 & 0.0 & 1.5 & 0.0 & 0,0 & 0.0 \\
\hline 2. Costa et al. 2000 & $\mathrm{AL}$ & 40 & 7.7 & 61.6 & 7.7 & 0.0 & 0.0 & 0.0 \\
\hline 3. Teixeira \& Moreira, 2010 & MG & 92 & 26.7 & 6.7 & 0 & 0.0 & 1.1 & 0.0 \\
\hline 4. $\quad$ Massara et al. 2004 & MG & 1,186 & 8.6 & 4.2 & 1.8 & 0.0 & 2.1 & 0.0 \\
\hline 5. Oliveira et al. 2012 & SE & 46 & 17.4 & 6.5 & 2.2 & 0.0 & 2.2 & 0.0 \\
\hline 6. $\quad$ Moraes 1997 & BA & 32 & 2.38 & 9.5 & 7.1 & 0.0 & 2.4 & 0.0 \\
\hline 7. Oliveira et al. 2012 & SE & 47 & 4.1 & 8.2 & 0.0 & 0.0 & 6.3 & 0.0 \\
\hline 8. Ttsuyuoka et al. 1999 & SE & 360 & 1.7 & 28.7 & 15.6 & 0.0 & 6.4 & 0.0 \\
\hline 9. Pereira 2010 & BA & 135 & 44.4 & 16.30 & 21.5 & 0.0 & 6.7 & 0.0 \\
\hline 10. Prado et al. 2001 & BA & 1,131 & 2.2 & 31.21 & 38.6 & 0.0 & 8.4 & 0.0 \\
\hline 11. Oliveira et al. 2012 & SE & 36 & 2.9 & 6.1 & 0.0 & 0.0 & 12.1 & 0.0 \\
\hline 12. Neto et al. 2012 & $\mathrm{PE}$ & 310 & 28.4 & 3.2 & 1.3 & 0.0 & 18.0 & 0.0 \\
\hline 13. Oliveira et al. 2012 & SE & 73 & 2.7 & 13.7 & 2.7 & 0.0 & 19.2 & 0.0 \\
\hline 14. Rollemberg et al. 2008 & SE & 19,400 & 10.9 & 16 & 26 & 0.0 & 22.0 & 0.0 \\
\hline 15. Oliveira et al. 2012 & SE & 55 & 3.6 & 27.3 & 1.8 & 0.0 & 23.6 & 0.0 \\
\hline 16. Rocha et al. 2010 & $\mathrm{AL}$ & 54 & 10.6 & 20.5 & 35.9 & 0.0 & 51.3 & 0.0 \\
\hline 17. Carvalho 2011 & MG & 487 & 5.1 & 0.82 & 0.0 & 0.0 & 8.2 & 0.2 \\
\hline 18. Torres 1985 & BA & 77 & 72.8 & 9.6 & 4.5 & 0.0 & 4.5 & 1.2 \\
\hline 19. Kanamura et al. 1998 & SP & 628 & 0.7 & 67.9 & 54.5 & 0.0 & 8.9 & 1.5 \\
\hline 20. Santos et al. 2005 & BA & 258 & 0.8 & 55.0 & 79.5 & 0.0 & 28.3 & 1.5 \\
\hline 21. Torres 1985 & MG & 124 & 9.6 & 2.4 & 0.8 & 0.0 & 21.0 & 1.6 \\
\hline 22. Torres 1985 & MG & 119 & 58.6 & 44.5 & 21.0 & 0.0 & 23.5 & 1.7 \\
\hline 23. Palmeira et al. 2010 & $\mathrm{AL}$ & 690 & 24.9 & 27.2 & 25.8 & 0.0 & 8.7 & 1.7 \\
\hline 24. Ludwig et al. 1999 & SP & 290 & 0.4 & 4.3 & 1.8 & 0.0 & 1.8 & 1.9 \\
\hline 25. Gonçalves et al. 1990 & $\mathrm{PE}$ & 140 & 90.3 & 59.4 & 73.5 & 0.0 & 11.0 & 2.0 \\
\hline 26. Barbosa and Silva. 1992 & $\mathrm{PE}$ & 105 & 92.0 & 81.0 & 62.0 & 0.0 & 32.0 & 2.0 \\
\hline 27. Oliveira et al. 2012 & SE & 44 & 2.3 & 18.2 & 4.5 & 0.0 & 2.3 & 2.3 \\
\hline 28. Assis et al. 2013 & MG & 88 & 23.9 & 2.3 & 2.3 & 0.0 & 60.2 & 2.3 \\
\hline 29. Gonçalves et al. 1990 & $\mathrm{PE}$ & 31 & 75.6 & 68.3 & 48.8 & 0.0 & 85.4 & 2.4 \\
\hline 30. Seixas et al. 2012 & BA & 200 & 1.0 & 25 & 10.5 & 0.0 & 1.5 & 2.5 \\
\hline 31. Costa et al. 2002 & BA & 155 & 5.8 & 43.1 & 15.3 & 0.0 & 35.8 & 2.6 \\
\hline 32. Gonçalves et al. 1990 & $\mathrm{PE}$ & 34 & 100.0 & 29.4 & 26.5 & 0.0 & 50.0 & 2.9 \\
\hline 33. Mati et al. 2011 & MG & 476 & 0.2 & 4,0 & 0.2 & 0.0 & 6.3 & 3.4 \\
\hline 34. Kruschewsky 2010 & BA & 500 & 62.0 & 37.4 & 43.4 & 0.0 & 33.7 & 3.5 \\
\hline 35. Torres 1985 & BA & 130 & 11.5 & 78.5 & 47.7 & 0.0 & 23.8 & 3.8 \\
\hline 36. Torres 1985 & BA & 229 & 24.4 & 42.4 & 18.8 & 0.0 & 11.4 & 3.9 \\
\hline 37. Filho et al. 2012 & MG & 2,161 & 0.36 & 21.5 & 9.6 & 0.0 & 12.2 & 4.5 \\
\hline 38. Torres 1985 & BA & 96 & 68.7 & 10.4 & 15.6 & 0.0 & 25.0 & 5.2 \\
\hline 39. Ferreira et al. 2002 & $\mathrm{AL}$ & 137 & 1.0 & 47.4 & 21.2 & 0.0 & 10.0 & 6. \\
\hline 40. Assis et al.2013 & MG & 99 & 32.3 & 2.0 & 0.0 & 0.0 & 30.3 & 6.1 \\
\hline 41. Barbosa \& Barbosa. 1998 & $\mathrm{PE}$ & 439 & 35.1 & 8.6 & 7.9 & 0.0 & 24.9 & 6.3 \\
\hline 42. Assis et al. 2013 & MG & 193 & 17.6 & 1.0 & 0.0 & 0.0 & 30.1 & 6.7 \\
\hline 43. Gonçalves et al. 1990 & $\mathrm{PE}$ & 193 & 75.7 & 66.7 & 76.9 & 0.0 & 83.1 & 7.8 \\
\hline 44. Okazaki et al. 1988 & $\mathrm{PE}$ & 651 & 11.2 & 62.1 & 60.1 & 0.0 & 47.0 & 9.6 \\
\hline 45. Cury et al. 1994 & MG & 864 & 15.4 & 11.1 & 0.4 & 0.0 & 8.7 & 12.9 \\
\hline
\end{tabular}

Abrev. : Sm = Schistosoma mansoni; Asc = Ascaris lumbricoides; Tri = Trichuris trichiura $;$ Tae = Taenia spp.; Hoo = Hookworm; Ss = Strongyloides stercoralis. Localities: AL = Alagoas; BA = Bahia; MG = Minas Gerais $; \mathrm{PE}=$ Pernambuco; $\mathrm{SE}=$ Sergipe $; \mathrm{SP}=$ São Paulo. Same author/year in several entries means different localities/population in the studied area of the state.

The precision of those results can be increased by stratification, so the Taenia spp. data was partitioned into Taenia spp. infection present $(n=24)$ or absent $(n=45)$. Because there were only a few cases registered for soil-transmitted helminths $(\mathrm{STH})$ infection absent, the score prevalence of each STH species were dichotomized into two levels as follows: score prevalence values consisting of scores that are above than a median (= "More"), and scores that are not above the median (= "Less"). The score prevalence of schistosomiasis) are presented as median and stratum differences of them were compared using Minitab software to calculate the results for a Kruskal-Wallis (KW) test. 
Box 2. Primary source of analysed data from Brazilian literature showing prevalence of helminhts in áreas with Taenia spp. transmission

\begin{tabular}{|l|c|c|c|c|c|c|c|c|}
\hline \multicolumn{1}{|c|}{ Author } & Localities & $\mathbf{N}$ & Sm & Asc & Tri & Tae & Hoo & Ss \\
\hline 1. Marinho 2008 & MG & 926 & $\mathbf{0 . 8}$ & 3.5 & 1.2 & 0.8 & 13.7 & 0.0 \\
\hline 2. Machado et al. 1996 & MG & 230 & $\mathbf{1 . 1}$ & 21.6 & 6.4 & 2.0 & 0.8 & 0.0 \\
\hline 3. Camargo-Neves et al. 1998 & SP & 400 & $\mathbf{5 . 0}$ & 16.5 & 17.7 & 0.2 & 0.2 & 0.0 \\
\hline 4. Enk et al. 2010 & MG & 1,061 & $\mathbf{1 1 . 2}$ & 1.6 & 0.0 & 1.8 & 10.4 & 0.0 \\
\hline 5. Roca 2011 & MG & 1,124 & $\mathbf{1 1 . 7}$ & 5.9 & 0.3 & 0.1 & 3.4 & 0.0 \\
\hline 6. Webster et al. 1997 & MG & 534 & $\mathbf{3 9 . 5}$ & 1.0 & 1.0 & 1.0 & 57.4 & 0.0 \\
\hline 7. Rocha et al. 2000* & MG & 1,441 & $\mathbf{0 . 0}$ & 4.8 & 0.9 & 0.2 & 0.6 & 0.1 \\
\hline 8. Chieffi et al. 1988 & SP & 913 & $\mathbf{0 . 2}$ & 40.8 & 31.2 & 0.2 & 1.3 & 0.4 \\
\hline 9. Mati et al. 2011 & MG & 341 & $\mathbf{1 . 5}$ & 0.3 & 0.0 & 0.3 & 2.0 & 0.6 \\
\hline 10. Magalhães et al. 2013 & MG & 93 & $\mathbf{4 . 1 6}$ & 34.2 & 0.27 & 0.1 & 2.3 & 1.07 \\
\hline 11. Rocha et al. 2000 & MG & 1,460 & $\mathbf{0 . 3 7}$ & 4.9 & 0.4 & 0.2 & 5.0 & 1.1 \\
\hline 12. Lopes et al. 2006 & PR & 264 & $\mathbf{1 . 5}$ & 10.2 & 6.1 & 1.1 & 3.4 & 1.1 \\
\hline 13. Ludwig et al. 1999 & SP & 11,573 & $\mathbf{0 . 1}$ & 3.8 & 1.6 & 0.5 & 1.5 & 1.5 \\
\hline 14. Cantuária et al. 2011 & MG & 110 & $\mathbf{1 . 8}$ & 0.0 & 0.0 & 1.8 & 0.0 & 1.8 \\
\hline 15. Ruela 2012 & MG & 46 & $\mathbf{8 . 7}$ & 3.0 & 0.0 & 2.2 & 4.3 & 2.2 \\
\hline 16. Ludwig et al. 1999 & SP & 2,585 & $\mathbf{0 . 2}$ & 13.1 & 5.9 & 0.1 & 1.6 & 2.2 \\
\hline 17. Ludwig et al. 1999 & SP & 607 & $\mathbf{0 . 2}$ & 8.9 & 4.8 & 0.2 & 1.5 & 2.8 \\
\hline 18. Costa et al. 1992 & RN & 7,012 & $\mathbf{0 . 9}$ & 31.2 & 27.9 & 11.2 & 11.2 & 3.4 \\
\hline 19. Olveira et al. 1974 & SP & 895 & $\mathbf{0 . 2}$ & 10.4 & 13.6 & 1.2 & 17.5 & 6.0 \\
\hline 20. Santos et al. 1990 & GO & 1,878 & $\mathbf{0 . 3}$ & 26.9 & 6.3 & 0.2 & 21.3 & 6.1 \\
\hline 21. Jardim-botelho et al. 2008 & MG & 1,113 & $\mathbf{4 5 . 2}$ & 50.7 & 1.1 & 0.2 & 69.8 & 8.1 \\
\hline 22. Oliveira et al. 2012 & SE & 36 & $\mathbf{2 2 . 2}$ & 52.8 & 5.6 & 2.8 & 22.2 & 8.3 \\
\hline 23. Anaruma et al 2007 & SL & 162 & $\mathbf{4 . 9}$ & 16.7 & 11.1 & 0.6 & 4.3 & 8.6 \\
\hline 24. Fontes et al. 2003 & & 1,020 & $\mathbf{2 . 4}$ & 57.0 & 59.1 & 1.4 & 51.3 & 14.0 \\
\hline
\end{tabular}

Abrev. : Sm = Schistosoma mansoni; Asc = Ascaris lumbricoides $;$ Tri = Trichuris trichiura $;$ Tae = Taenia spp.; Hoo = Hookworm; Ss = Strongyloides stercoralis. Localities: AL = Alagoas; GO= Goiás $;$ MG = Minas Gerais; PR= Paraná ; RN= Rio Grande do Norte ; SE = Sergipe; SP = São Paulo. Same author/year in several entries means different localities/population in the studied area of the state.

\section{RESUlts}

The method of sampling attempts to total 69 surveys positive for $S$. mansoni infection and the estimate of the average prevalence of $S$. mansoni infection is 5.46 .

There were 35,832 persons in prevalence surveys where Taenia spp. is present and 32,836 undertaken among this parasite is absent (or in 24 and 45 sampled localities respectively, source data in boxes 3 and 4). When comparing the median prevalence of schistosomiasis in a region without Taenia spp. occurrence to a region with Taenia spp. infection (that is, $11.20 \mathrm{vs} 1.51$ ) the score prevalence of $S$. mansoni infection does exhibit different distribution (Table 1).

Table1. Median prevalence of schistosomiasis with or without Taenia spp. Infection in different regions

\begin{tabular}{|c|c|c|c|}
\hline Infection by Taenia spp. & Number of survey & Number of persons & Prevalence of S. mansoni $^{*}$ \\
\hline No & 45 & 32,836 & 11.20 \\
\hline Yes & 24 & 35,832 & 1.51 \\
\hline
\end{tabular}

$* K W=12.13 ; P=0.000 ; D F=1$

Further, it was applied stratification, a sampling procedure in which the population is divided into subgroups or strata within each of which an independent sample is selected.

In such case stratification of the data is a statistical strategy for controlling variables that distorts an outcome of interest, the prevalence of $S$. mansoni. A parasite with potential granulomatous character, the Taenia spp. (presence/absence), was variable 1. The prevalence of zoonotic Strongyloides infection, another parasite with potential granulomatous character, was fitted as the second variable with two prevalence levels (either "More" or "Less"). A third variable was the major geo-helminths without noticeable granulomatous character, stratified by species namely Ascaris, Trichuris, and hookworms, also with two levels of prevalence (either "More" or "Less"). So, the data can be represented in a table format easy to visualize what happens with the average prevalence of schistosomiasis in the strata or subgroups (Table 2). 
Table2. helminth species as factors that contribute to the variability in median prevalence of Schistosoma mansoni infection estimates

\begin{tabular}{|c|c|c|c|c|c|c|c|}
\hline \multirow{2}{*}{\multicolumn{2}{|c|}{ Route of infection }} & \multirow[t]{2}{*}{$\begin{array}{l}\text { Prevalence } \\
\text { levels }\end{array}$} & \multicolumn{2}{|c|}{$\begin{array}{l}\text { Taenia } \text { spp. positive with } \\
\text { Strongyloides }\end{array}$} & \multicolumn{2}{|c|}{$\begin{array}{l}\text { Taenia spp. negative with } \\
\text { Strongyloides }\end{array}$} & \multirow[t]{2}{*}{$p$-Value } \\
\hline & & & "More" & "Less" & "More" & “"Less" & \\
\hline \multirow[t]{4}{*}{ A) Oral } & \multirow[t]{2}{*}{ Ascaris } & "More" * & $1.6(8) * *$ & $2.6(4)$ & $24.4(13)$ & $3.6(9)$ & \multirow[t]{2}{*}{0.028} \\
\hline & & "Less"' & $1.0(4)$ & $1.5(8)$ & $17.6(9)$ & $10.2(14)$ & \\
\hline & \multirow[t]{2}{*}{ Trichuris } & "More" & $0.6(8)$ & $1.3(4)$ & $24.4(\mathbf{1 3})$ & $10.6(9)$ & \multirow[t]{2}{*}{0.009} \\
\hline & & "Less"' & $5.2(4)$ & $2.8(8)$ & $15.4(9)$ & $8.1 \quad(14)$ & \\
\hline \multirow[t]{2}{*}{ B) Skin } & \multirow[t]{2}{*}{ Hookworm } & "More" & $3.6(8)$ & $6.0(4)$ & $33.7(\mathbf{1 4})$ & $10.1(\mathbf{8})$ & \multirow[t]{2}{*}{0.001} \\
\hline & & "Less"' & $1.0(4)$ & $1.5(8)$ & $1.6(8)$ & $7.7(15)$ & \\
\hline
\end{tabular}

*The score prevalence of Ascaris, Trichuris and hookworm species was dichotomized into two levels: a) The score prevalence values that are above than a median (="More"), and scores that are below the median (=“Less"). **Median; $(\mathrm{N})=$ samples .

Statistically, the expectation is that the median prevalence of $S$. mansoni infection does not differ from one another. However, looking at the median prevalence of $S$. mansoni infection they vary so much that one might wonder whether each group of strata distorts the association of parasite variables with the prevalence of schistosomiasis. Overall, the score prevalence of schistosomiasis in a region with Taenia spp. the median prevalence of $S$. mansoni infection does exhibit lower values regardless of Strongyloides, Ascaris, Trichuris, or hookworms. There was statistically different distribution of scores of prevalence of schistosomiasis since the $p$-value results for Ascaris, Trichuris, or hookworms strata were $0.028,0.009$, and 0.001 , respectively.

\section{DISCUSSION}

Despite S. mansoni infections, S. stercoralis and Taenia spp. are phylogenetically unrelated parasites them thought to be some similarities. The infections are primarily localized in the digestive tract, but the nervous system is the other involved site [12-15]. Also, anti-complement system activity has been demonstrated in the Taenia taeniaeformis [16] as well as separated from sera of a S. mansoni infection or a bacterial disease $[17,18]$.

When data from a variety of bibliographical sources have been lumped together, such as different parasitological condition, prevalence and some others, data analysis require separating different groups or strata $[4,19,20]$. In this present stratified study, the lower average prevalence of $S$. mansoni infection is clear to find strata on Taenia spp. positive grade than negative. It was observed that a higher score average prevalence of schistosomiasis was also observed in Taenia spp. negative strata that have "More" prevalence of Strongyloides infection. For the first time, it was shown the risk of Taenia spp. and Strongyloides infections, as an environmental indicator to guide the prevalence of $S$. mansoni infection in a fashion major soil-transmitted helmints (Ascaris, Trichuris, and hookworms) dependent manner. Since $S$. mansoni and studied helminth species do not interact directly with one another, the effects of immunological response can not be excluded [7,12,21]. In another line of the study also it was referred on the possible existence of a negative association between $S$. mansoni and Ascaris or Trichuris [4,5,6].

Unfortunately, no similar studies applying collective analysis in S. mansoni areas with zoonotic species of helminths that induce granulomatous inflammation was found to be compared. Concerning the co-infection with S. mansoni and Strongyloides the majority of the studies have been performed mainly in HIV infection [22-24].

Lastly, in the first column in Table 2, in the Ascaris group, these strata were contaminated by the "hidden" occurrence of the Trichuris and hookworms and so on. Despite the present model of collective analysis may be important to obtain overall information about the functional form of the prevalence of $S$. mansoni infection other factors that contribute to the variability in the prevalence of S. mansoni infection. These factors were well known namely socio-economic, human behavior, age, nutritional, environmental, demographic, ecological characteristics, and the lack of accurate diagnostic tools could also affect the results.

\section{CONCLUSION}

We conclude from the present analysed data that the median prevalence of schistosomiasis in a region 
with or without infection by Taenia spp. does exhibit different distribution pattern regardless the infection by Strongyloides, Ascaris, Trichuris, or hookworm.

\section{ACKNOWLEDGMENTS}

The authors are grateful to Sonia F. S. Souza for valuable help with the bibliographic search and compiling data and Dr. Stefan Geiger for critical reading of the first draft of the manuscript. To the Conselho Nacional de Desenvolvimento Científico e Tecnológico-CNPq, Brasil for research fellowship to ALM.

\section{AUTHORS' CONTRIBUTIONS}

MC conceived, designed the study, compiled the data and with ALM drafted the first version of manuscript; GSA analyzed and interpreted the data. All authors read, critically revised and approved the final manuscript.

\section{FUNDING}

The authors received no specific funding for this work.

\section{CONFLICT OF INTEREST STATEMENT}

The authors declare that they have no conflict of interest.

\section{Data Availlability}

The authors declare that the data supporting the findings of the present study are available within the article and if necessary for further information, from the corresponding author upon request.

\section{REFERENCES}

[1] World Health Organization. Global plan to combat neglected tropical diseases 2008-2015. (2007). Available: http://www.who.int/neglected_diseases/NTD20Global20plan_20January202007.pdf. Accessed 27 January 2009.

[2] Olsen A., van Lieshout L., Marti H., Polderman T., Polman K., Steinmann P., Stothard R., Thybo S., Verweij J. J. and Magnussen P. Strongyloidiasis, the most neglected of the neglected tropical diseases? Trans. R. Soc. Trop. Med. Hyg. 103(10), 967-72, (2009).

[3] Mati V. L. T.; Raso P. and Melo A. L. Strongyloides stercoralis infection in marmosets: Replication of complicated and uncomplicated human disease and parasite biology. Parasite \& Vectors, 7, 579-596, (2014).

[4] Chamone M., Marques C. A., Atuncar G. S., Pereira A. L. and Pereira L. H. Are there interactions between schistosomes and intestinal nematodes? Trans. R. Soc. Trop. Med. Hyg. 84, 557-558, (1990).

[5] Chamone M., Erichsen E., Atuncar G., and Melo, A. L. Hidden association between Schistosoma mansoni and Ascaris lumbricoides infections. Rev. Ciên. Méd. Biol. 10,146-153, (2012).

[6] Fleming F. M., Brooker S., Geiger S. M., Caldas I. R., Corrêa-Oliveira R., Hotez P. and Bethony J. M. Synergistic associations between hookworm and other helminth species in a rural community in Brazil. Trop. Med. Int. Health. 11, 56-64, (2006).

[7] Geiger S. M. Immuno-epidemiology of Schistosoma mansoni infections in endemic populations coinfected with soil-transmitted helminths: Present knowledge, challenges, and the need for further studies. Acta Trop. 108, 118-123, (2008). https://doi.org/10.1016/j.actatropica.2008.05.012

[8] Keiser J., N'goran E. K, Singer B. H., Lengeler C., Tanner M. and Utzinger J. Association between Schistosoma mansoni and hookworm infections among schoolchildren in Côte d'Ivore. Acta Trop. 84, 31 41, (2002).

[9] Raso G., Vounatsou P., Singer B. H., N'Goran E. K., Tanner M. and Utzinger J. An integrated approach for risk profiling and spatial prediction of schistosoma mansoni-hookworm coinfection. PNAS. 103, 6934-6939, (2006).

[10] Webster M., Corrêa-Oliveira R., Gazzinelli G., Viana I. R., Fraga L. A., Silveira A. M. and Dunne D. W. Factors affecting high and low human IgE responses to schistosome worm antigens in an area of Brazil endemic for Schistosoma mansoni and hookworm. Am. J. Trop. Med. Hyg. 57, 487-494, (1997).

[11] Brooker S., Booth M., Guyatt H. Comparisons of schistosome and geohelminth infection prevalences in school-aged children from selected areas of Africa: implications for rapid assessment and combined control. Trans. R. Soc. Trop. Med. Hyg. 93, 125-26, (1999). http://dx.doi.org/10.1016/S00359203(99)90281-X. 
[12] Iudici Neto F., Pianetti-Filho G., Araújo R. N. and Nascimento E. Immunodiagnosis of human neurocysticercosis by using semi-purified scolex antigens from Taenia solium cysticerci. Rev. Soc. Bras. Med. Trop. 40,163-169, (2007).

[13] Moura E. B., Maia M. O., Ghazi M. A., Ferreira F. and Pinhati H. M. Salvage treatment of disseminated strongyloidiasis in an immunocompromised patient: therapy success with subcutaneous ivermectin. Braz. J. Infec. Dis. 16, 479-481, (2012).

[14] Pittella J. E. H. Neuroschistosomiasis. Brain Pathol. 7, 649-662, (1997).

[15] Woll F., Gotuzzo E. and Montes M. Strongyloides stercoralis infection complicating the central nervous system. Handb. Clin. Neurol. 114, 229-34, (2013).

[16] Hammerberg B., Williams J. F. Interaction between Taenia taeniaeformis and the complement system. J. Immunol. 120, 1033-1038, (1978).

[17] Nascimento B. C. and Chamone M. The separation of complement inhibitors from patients with schistosomiasis or Chagas' disease by gel filtration on Sephadex G-200: a preliminary study. Braz. J. Med. Biol. Res. 21, 295-299, (1988).

[18] Nascimento B. C., Cisalpino E. O. and Chamone M. Blocking of haemolytic complement by heterogeneous factors present in lepromatous leprosy. Lepr. Rev. 60, 68-70, (1989).

[19] Alves-Oliveira L., Chamone M., Marques C. A., Nascimento B. C. and Coelho P. M. Antibodies reactivity in human Schistosoma mansoni disease: detection and functional activity. Ann. Trop. Med. Parasitol. 82, 591-595, (1988).

[20] Chamone M., Atuncar G. S., Coelho P. M. Thermostability of heterophile antibodies from human sera infected with Schistosoma mansoni and geo-helminths. An immuno-metric statistical analysis. Rev. Inst. Med. Trop. São Paulo. 48,157-165, (2006).

[21] Geiger S. M., Douglas, N. E. A., Fujiwara, R. T. Brooker, S.; Cundill, B.; Diemert, D. J.; Correa-Oliveira, R. and Bethony, J. M. Necator Americanus and helminth co-infections: further down-modulation of hookworm-specific Type 1 immune responses. PLoS Neglected Tropical Diseases 5, e1280, (2011).

[22] Blatt, J. M. and Cantos, G. A. Evaluation of techniques for the diagnosis of Strongyloides stercoralis in human immunodeficiency virus (HIV) positive and HIV negative individuals in the city of Itajaí, Brazil. Braz. J. Infect. Dis. 7, 402-408, (2003).

[23] Paula, F. M. and Costa-Cruz, J. M. Epidemiological aspects of strongyloidiasis in Brazil. Parasitology. 138, 1331-1340, (2011). http://dx.doi.org/10.1017/S003118201100120X

[24] Sadlier C. M., Brown A., Lambert J. S., Sheehan G. and Mallon P. W. G. Seroprevalence of Schistosomiasis and Strongyloides infection in HIV-infected patients from endemic areas attending a European infectious diseases clinic. AIDS Res. and Ther. 10, 23-27, (2013).

Citation: Alan Lane de Melo et al., "The Prevalence of Schistosoma mansoni is affected by Taenia spp. and Soil-transmitted Helminths", International Journal of Research Studies in Biosciences, 8(5), pp. 7-12. DOI:https://doi.org/10.20431/2349-0365.0805002

Copyright: (C) 2020 Authors, This is an open-access article distributed under the terms of the Creative Commons Attribution License, which permits unrestricted use, distribution, and reproduction in any medium, provided the original author and source are credited. 